\title{
Syndactyly-camptodactyly and clinodactyly of fifth fingers-bifid toes syndrome
}

INSERM

\section{Source}

INSERM. (1999). Orphanet: an online rare disease and orphan drug data base. Syndactylycamptodactyly and clinodactyly of fifth fingers-bifid toes syndrome. ORPHA:357332

A rare, genetic, congenital limb malformation syndrome characterized by a unique combination of bilateral, symmetrical camptodactyly and clinodactyly of 5th fingers, mesoaxial camptodactyly of toes, and ulnar deviation of 3rd fingers. Additional variable manifestations include bifid toes and severe syndactyly, or synpolydactyly, involving all digits of hands and feet. 